\title{
O INTERNALISMO SEMÂNTICO DE CHOMSKY
}

\author{
Cícero Antônio Cavalcante Barroso \\ Universidade Federal do Ceará (Cariri)
}

Resumo: Noam Chomsky influenciou decisivamente o desenvolvimento da linguística e da psicologia no século XX, e foi um dos fundadores da ciência cognitiva. Na filosofia, sua influência também foi importante, mas a maior parte de suas observações sobre a semântica da linguagem natural nunca foi aceita pela corrente dominante da filosofia da linguagem. 0 externalismo dos próceres dessa corrente era simplesmente incompativel com a abordagem internalista que Chomsky propôs para o estudo da linguagem desde o início. Neste artigo, coloco em relevo os pontos nos quais a filosofia externalista da linguagem e o internalismo chomskyano se atritam de modo mais contundente, explicitando os argumentos que Chomsky apresenta para defender sua posição e atacar a visão externalista.

Palavras-chave: Noam Chomsky, internalismo semântico, externalismo semântico.

Abstract: Noam Chomsky influenced the Linguistics and Psychology development decisively in the twentieth century, and was one of the cognitive science founders. In philosophy, his influence was important too, but the most of his observations about natural language semantics never was accepted by mainstream philosophy of language. The externalism of the leading persons in that philosophical current was just incompatible with the internalist approach proposed at the outset by Chomsky to language study. In this article, I highlight the points in which the externalist philosophy of language and the Chomskyan internalism get attrition in a more impressive way by making explicit the arguments that Chomsky presents to defend your position and to attack the externalist view.

Keywords: Noam Chomsky, semantic internalism, semantic externalism.

\section{Introdução}

Alguns filósofos acreditam que fatos semânticos podem ser explicados de forma inteiramente satisfatória levando-se em consideração tão somente as 
interações da linguagem com o mundo externo e com certas práticas sociais das comunidades de falantes, sem que seja preciso fazer menção a qualquer relação entre o uso da linguagem e os estados mentais dos seus usuários. Outros filósofos, porém, insistem que nosso uso da linguagem depende essencialmente de alguns dos nossos processos mentais e declaram que toda explicação semântica que desconsidera essa dependência será inevitavelmente falha. Creio ser correto caracterizar o externalismo semântico (ou linguístico) como a posição dos filósofos do primeiro grupo e o internalismo semântico (ou linguístico) como a posição dos filósofos do segundo grupo. ${ }^{1}$

Noam Chomsky é mais conhecido por seu trabalho no campo da linguística e por suas opiniões políticas, mas ele é também um internalista dos mais combativos, com argumentos robustos e desconcertantes em favor de sua posição e contra o externalismo semântico. Em sua concepção, os aspectos essenciais da linguagem são todos determinados por estados mentais específicos e alguém que queira explicar o fenômeno da linguagem precisa explicar primeiramente esses estados. Ele afirma que uma verdadeira ciência da linguagem "procura desenterrar a natureza e as propriedades de tais estados, seu desenvolvimento e variedade, e sua base na herança biológica inata" (CHOMSKY, 2000, p. 2).

Essa concepção que Chomsky tem da linguagem e da ciência da linguagem permanece em grande parte incompatível com algumas das teses mais influentes da filosofia da linguagem contemporânea. Neste artigo, examinarei as principais críticas chomskyanas a tais teses. Antes, porém, falarei sobre algumas ideias de Chomsky que são essenciais para a compreensão do seu internalismo linguístico.

\section{As bases internalistas da linguística chomskyana}

Um fato foi essencial para que Chomsky adotasse uma perspectiva internalista sobre a linguagem, o fato de que nós aprendemos a nossa primeira língua sem que ninguém nos ensine. Antes da gramática gerativa transformacional (a teoria linguística chomskyana) a explicação mais aceita para esse fato era a de que, embora os bebês não tenham aulas para aprender sua primeira língua, eles observam como as pessoas se comunicam e

\footnotetext{
1 Em outras caracterizações, o externalista é retratado como alguém que sustenta que a determinação do significado e da referência das palavras depende pelo menos em parte de fatores externos. Entretanto, creio que a caracterização dada no primeiro parágrafo está mais de acordo com as declarações efetivas de externalistas fundadores como Putnam (PUTNAM, 1973 e 1979) e Burge (BURGE, 1979).
} 
aprendem por imitação e condicionamento. Chomsky notou que essa explicação era muito simplista e propôs então que os bebês já nascem com um tipo de teoria de linguagem e aprendem sua língua materna testando essa teoria. O fato de crianças de todos os lugares do mundo cometerem os mesmos tipos de erro quando estão aprendendo a falar seria uma evidência disso. O fato de elas desenvolverem uma competência linguística mínima aproximadamente no mesmo espaço de tempo também seria uma indicação. A evidência principal, porém, é o fato de que uma língua natural é uma estrutura extremamente complexa. O estímulo linguístico que nós recebemos é muito pobre para explicar a exuberância da linguagem que nós apresentamos em poucos anos de vida. É preciso postular que a estrutura básica da linguagem está enraizada no nosso aparato cognitivo. Se não fosse pelo fato de possuirmos uma gramática embutida em nossas mentes, aprender uma língua seria uma tarefa absurdamente difícil ou mesmo impossível. É ancorado nessas evidências que Chomsky enuncia seu nativismo linguístico.

Ao postular que a estrutura básica da linguagem é inata, Chomsky está assumindo que a mente humana é um tipo de sistema computacional composto de diferentes programas interligados. Há programas responsáveis pela visão, pelas ações motoras, pelo raciocínio lógico e assim por diante. Em particular, há um sistema mental responsável pela linguagem. Chomsky o chama de "faculdade da linguagem". A faculdade da linguagem deve executar e gerenciar tarefas múltiplas tais como articulação e interpretação de fonemas, representação de aspectos semânticos, aplicação de regras de formação de expressões complexas etc. O fato de que nós humanos nascemos equipados com esse sistema é o que explica nossa capacidade de aprender e dominar uma língua. Em outras palavras, é isso que explica nossa competência e desempenho linguísticos.

A tese de que há uma faculdade da linguagem implica na afirmação de que há uma gramática universal, ou seja, há princípios que determinam as características fundamentais de todas as línguas naturais. A justificativa é a seguinte: se há estratégias de aprendizagem específicas para a aquisição da nossa primeira língua, isso é porque as rotinas envolvidas nessas estratégias devem nos predispor para assimilação da gramática da língua. Acontece que há uma grande diversidade de línguas naturais, mas a faculdade da linguagem deve ser a mesma em toda a espécie humana. Dessa forma, a mesma faculdade que possibilita que uma criança aprenda alemão, possibilita que outra criança aprenda swahili. Daí é possível concluir que todas essas línguas, aparentemente tão diferentes, em um nível mais profundo de análise, estão fundadas sobre os mesmos princípios, e são esses princípios que a faculdade 
da linguagem nos dá por antecipação. São esses princípios que constituem a gramática universal, o estado inicial da faculdade de linguagem. Tal gramática é, portanto, uma teoria que todo ser humano traz embutida na sua mente e que modela os modos que a linguagem pode assumir. Quando uma criança é exposta a uma língua natural, ela começa a testar sua teoria internalizada. À medida que os dados empíricos confirmam suas hipóteses, ela vai adquirindo domínio sobre a sua língua materna. De acordo com Chomsky, se não fosse assim, aprender a primeira língua seria uma tarefa virtualmente impossível.

Desde que foi proposta, a hipótese da gramática universal foi objeto de muita discussão. E Chomsky de fato sempre fez questão de defender sua visão internalista da linguagem e atacar as posições contrárias. Seu ataque ao behaviorismo, por exemplo, foi arrasador. Considera-se que seu review do livro Verbal Behavior, de B. F. Skinner, contribuiu de forma decisiva para a derrocada da abordagem behaviorista da linguagem. Nesse livro, Skinner tenta fazer uma "análise funcional" do comportamento verbal, ou seja, tenta descrever esse comportamento como uma função de estímulos externos em respostas verbais. Para dar essa descrição, ele recorre a noções como estímulo, reforço, privação etc. O que Chomsky faz em seu review é examinar de forma detalhada cada um dos conceitos utilizados por Skinner, mostrando ao final que "se nós tomamos seus termos em seu significado literal, a [sua] descrição não cobre quase nenhum aspecto do comportamento verbal, e se nós os tomamos metaforicamente, a descrição não acrescenta nada às formulações tradicionais" (CHOMSKY, 1964a, p. 574). Além disso, ele mostra que há alguns aspectos do comportamento verbal que nenhuma teoria linguística séria pode deixar de explicar. Em primeiro lugar, é preciso explicar como podemos fazer e entender proferimentos não familiares. A linguagem nos franqueia um repertório virtualmente infinito de proferimentos e, de fato, muitos proferimentos que ouvimos são inéditos. Simplesmente não é razoável conceber nosso reconhecimento da gramaticalidade de tais proferimentos como uma mera resposta a estímulos externos. Em segundo lugar, é necessário explicar o fenômeno da explosão linguística, isto é, o fato de todas as crianças normais apresentarem já com pouca idade uma competência linguística considerável, muito embora a complexidade formal de uma língua seja monstruosa e o estímulo verbal externo que elas recebem seja relativamente pobre. A teoria de Skinner era flagrantemente deficitária no tocante à explicação desses aspectos do comportamento verbal.

Mas as críticas chomskyanas ao estudo behaviorista da linguagem não param por aí. Elas reaparecem em muitos outros lugares da obra de Chomsky. Em Language and Mind, de 1968, por exemplo, ele diz o seguinte: 


\begin{abstract}
Nenhuma pessoa sã duvida que o comportamento ofereça grande parte da evidência para este estudo [da linguagem]... Mas o termo "ciência do comportamento" sugere uma mudança de ênfase não tão sutil em direção à evidência em si, e na direção contrária dos princípios subjacentes mais profundos e das estruturas mentais abstratas que podem ser iluminadas por essa evidência de comportamento (CHOMSKY, 1968, p. 58).
\end{abstract}

Vê-se assim que, para Chomsky, o grande problema do behaviorismo é permanecer em um nível superficial de análise. O psicólogo behaviorista tem licença para investigar o comportamento, mas não os mecanismos internos que provocam esse comportamento em um indivíduo. Esse tipo de análise é incompatível com a hipótese inatista da linguagem. O confronto de Chomsky com o behaviorismo metodológico era inevitável uma vez que sua visão da linguagem estava toda sedimentada sobre pressupostos mentalistas. Pela mesma razão, um ataque a certas teses filosóficas sobre a linguagem não podia deixar de acontecer. Nos parágrafos seguintes, serão apresentados os principais argumentos que Chomsky usou nesse ataque.

\title{
Observações críticas de Chomsky
}

O internalismo de Chomsky o leva a rejeitar teses filosóficas veneráveis. Entre essas teses, importa destacar duas. A primeira é a tese de que a linguagem é um construto público, uma propriedade de comunidade. A segunda é a tese de que, basicamente, as expressões da linguagem denotam coisas do mundo.

A posição de Chomsky em relação à primeira tese nos é apresentada por Neil Smith no prefácio de New Horizons in the Study of Language and Mind. Eis o que é dito:

Boa parte da tradição filosófica tem enfocado a linguagem como um construto público do qual os indivíduos têm conhecimento parcial. Esta visão se preocupa com a relação entre linguagem e realidade externa: a relação palavra-mundo que sustenta as teorias padrão de semântica referencial. Em oposição a esta tradição, Chomsky defende em detalhe, e com uma série de análises linguísticas imaginativas, a noção de que o conhecimento da linguagem é individual, interno à mente/cérebro. Segue que o próprio estudo da linguagem deve 
tratar desse construto mental, uma entidade teorética que ele refere com o neologismo "I-linguagem", uma propriedade interna de um indivíduo (SMITH, 2000 apud CHOMSKY, 2000, p. vii).

Essa posição de Chomsky está inteiramente de acordo com o seu nativismo linguístico, de fato é uma consequência dele. Se a linguagem que eu falo é produzida pela minha faculdade de linguagem, então obviamente ela é minha linguagem individual, é uma propriedade privada, não pública. Ela se origina dentro de mim, é um estado de minha faculdade de linguagem. $\mathrm{E}$ assim é com toda a espécie humana. A linguagem não é algo que esteja fora dos indivíduos. Cada indivíduo tem a sua linguagem. Cada criança que aprende uma língua está, na prática, recriando essa língua a partir de seus próprios recursos internos. Em vista disso, a rigor, não há nenhuma linguagem pública, nada que se possa chamar de "Português", por exemplo, algo externo que uma comunidade de falantes compartilha. O que existe é o Português do João, o Português do José etc. Línguas individuais com uma quantidade suficiente de similaridades para que João e José se entendam.

Como Neil Smith ressalta na citação acima, essa posição é francamente antagônica à posição filosófica majoritária. A ideia de que a linguagem é algo público está presente em toda a história da filosofia analítica. De fato, esse foi um dos pressupostos do movimento analítico. Por que os analíticos dos primeiros tempos fizeram da análise da linguagem a tarefa fundamental da filosofia? Sem dúvida, uma das razões para isso é que eles acreditavam que, diferentemente de ideias, a linguagem é pública e por isso pode ser submetida a um exame objetivo. Supostamente, o filósofo poderia analisar a linguagem sem precisar considerar o que se passa internamente com as pessoas enquanto elas usam a linguagem.

Mas, para além das motivações antipsicologistas dos primeiros tempos, é muito intuitivo pensar na linguagem como uma propriedade compartilhada por uma comunidade. Os filósofos que pensam assim alegam que, se a linguagem não fosse um construto público, a comunicação seria impossível. Se as pessoas não compartilhassem uma linguagem, elas simplesmente não se entenderiam. A ideia é que as pessoas que falam português, por exemplo, se entendem, ou pelo menos podem se entender, porque possuem uma linguagem comum. Indivíduos que não falam português não entendem uma pessoa que só fala português porque não compartilham uma linguagem com essa pessoa.

Em todo caso, Chomsky rejeita a ideia de que a publicidade da linguagem ou dos significados seja necessária para explicar a possibilidade de 
comunicação. Ele replica aos defensores da tese de que a linguagem é pública sugerindo ironicamente que eles deveriam também postular a necessidade de uma "pronúncia pública". Segundo ele, "a única 'estrutura compartilhada' de modo geral entre humanos (possivelmente) é o estado inicial da linguagem. Além disso, nós podemos esperar apenas aproximações...” (CHOMSKY, 2000, p. 30). Para ele, essas aproximações são tudo o que precisamos para poder nos comunicar.

De acordo com a análise chomskyana, quando duas pessoas crescem juntas em determinado ambiente, muitos dos inputs que alimentam suas faculdades de linguagem são bastante similares. Dessa forma, apesar dessas pessoas desenvolverem I-linguagens diferentes, elas são capazes de interpretar o que cada uma diz com base nas suas próprias computações internas. Segundo Chomsky, nós criamos os nossos próprios significados e assumimos que os significados dos outros são iguais aos nossos. Em outras palavras, nós atribuímos aos outros as construções de nossas próprias mentes. É assim que duas pessoas podem se entender com base apenas em suas linguagens individuais, sem que precisem compartilhar uma linguagem comum. Para Chomsky, quando se diz que duas pessoas falam a mesma língua, isso nunca é literalmente verdade, essas pessoas na realidade falam apenas línguas parecidas. Essa proximidade basta para explicar como a comunicação entre elas é possível.

Mas a ideia de uma linguagem pública é adotada não só para explicar como as pessoas se entendem, mas também para explicar como as pessoas aprendem uma linguagem. Uma linguagem pública é uma linguagem externa. Não é propriedade de um indivíduo, mas de uma comunidade. Por essa mesma razão, aprender uma linguagem seria assimilar algo que vem de fora.

A despeito dessas alegações, Chomsky defende que aprender uma língua não significa assimilar uma estrutura externa. Não é necessário postular a existência de uma língua como português, por exemplo, para que faça sentido dizer que um indivíduo $\mathrm{X}$ está aprendendo português. Supor que uma pessoa que está aprendendo português está se aproximando de uma entidade imaginária não esclarece nada. Essa é uma forma não científica de falar sobre a linguagem. Para ele, esses modos de falar ordinários não devem ser invocados para esclarecer a questão de como uma pessoa chega a dominar uma língua.

De acordo com o ponto de vista chomskyano, o domínio de uma nova língua é determinado pela nossa faculdade de linguagem. O que adquirimos de fora não é uma língua, mas experiências apropriadas que acionam nossa faculdade de linguagem. Essa, por sua vez, cria nossa própria língua individual, como, por exemplo, nosso português individual. E mesmo 
as experiências que acionam a faculdade de linguagem de um indivíduo só são eficazes porque são moldadas pelos recursos inatos da sua mente/cérebro, sendo interpretadas de acordo com a sua I-linguagem. Por isso é preciso investigar a anatomia da mente e as I-linguagens individuais. Somente numa I-linguagem uma palavra tem valor semântico. A tese de Chomsky é a de que, se nós divorciarmos um termo das propriedades que ele tem numa Ilinguagem particular e acreditarmos que sua referência é fixada numa linguagem pública comum, nós fazemos um movimento que vai além dos limites da investigação naturalista, em outras palavras, nós fazemos um movimento injustificado.

De qualquer modo, os filósofos que tratam a linguagem como uma coisa pública acham que dessa forma estão enfocando o aspecto fundamental da linguagem, a saber, seu aspecto social. Para eles, a linguagem é uma propriedade da comunidade e não dos indivíduos. Essa propriedade é caracterizada por um comportamento linguístico uniforme dos membros da comunidade. Para que alguém venha a assimilar a linguagem dessa comunidade, basta observar esse comportamento. Com efeito, é isso que Quine sugere quando narra a estória do "linguista de campo" no capítulo 2 de Palavra e Objeto (p. 53-55). Segundo Quine, se um linguista quer aprender uma língua completamente desconhecida, ele não precisa analisar nenhuma evidência psicológica. Ele pode aprender a língua através do contato direto com os falantes, e a única coisa que ele precisa observar em sua pesquisa é o comportamento linguístico desses falantes.

Ao analisar esse exemplo de Quine, Chomsky começa chamando a atenção para o fato de que a expressão "linguista de campo" não pode se referir àqueles que realmente trabalham com linguística. A expressão mais parece ter um caráter normativo, designando o tipo de linguista que se ajustaria ao holismo e ao behaviorismo quineanos. Chomsky explica que o approach internalista é o que os cientistas seguem na prática para o estudo da linguagem. Estudos sociolinguísticos podem ser feitos e são externalistas por definição, mas não é isso que explica como a linguagem é adquirida, compreendida e usada.

Ademais, Chomsky discorda do preceito de que o linguista pode usar evidência linguística, mas não evidência psicológica. Ele afirma que essa, como outras restrições que se querem impor ao linguista só "refletem uma forma de dualismo, uma insistência em que nós não devemos tratar $\mathrm{o}$ domínio do mental” (CHOMSKY, 2000, p. 140). E continua dizendo que, se o linguista tivesse de se adequar a estreiteza terminológica de Quine, seria melhor abandonar a linguística. Para ele, é um fato natural que o cérebro 
apresenta certas propriedades quando nós construímos sistemas de regras e coisas assim. Simplesmente não faz sentido vetar o estudo desse fato.

De forma semelhante, Chomsky critica Dummett quando este diz que linguagem é uma "prática que aprendemos dos outros e é constituída por regras que seguimos de acordo com o costume social" (CHOMSKY, 2000, p. 48). Também de acordo com essa perspectiva, a linguagem seria independente de qualquer falante particular. Os falantes particulares teriam apenas uma apreensão parcial de uma linguagem (tal como inglês ou japonês). Chomsky argumenta que na prática empírica o conceito de linguagem dummettiano é inútil. Segundo ele, "o conceito de linguagem que Dummett considera essencial envolve elementos sociopolíticos, históricos, culturais e normativoteleológicos complexos e obscuros" (CHOMSKY, 2000, p. 49). Entre esses elementos estão os conceitos de "mal uso da linguagem", "norma" e "comunidade". Tais conceitos, na opinião de Chomsky, não são bem definidos. Quando se diz, por exemplo, que X segue uma regra se e somente se $X$ se ajusta à prática ou às normas da comunidade, a palavra "comunidade" não acrescenta nada aqui, ele observa. Sem posteriores especificações, o uso da palavra deixa a análise vácua. Segundo ele, se alguém segue ou não o que nós chamamos de "normas da comunidade" ou "prática social" é com base na sua I-linguagem internalizada.

Destarte, o que realmente deve ser investigado é a faculdade de linguagem e seu estado inicial. É dela que provém o nosso conhecimento da linguagem. São os fatores sociais envolvidos no uso da linguagem que devem ser interpretados à luz de uma teoria da faculdade de linguagem, não o contrário. O estado inicial da linguagem não depende do costume social. A experiência fixa algumas opções que o estado inicial deixa em aberto, mas uma vez que isso é fixado, as escolhas futuras podem ser feitas sem nenhum recurso à prática social.

Essas, em suma, são as principais críticas que Chomsky faz à tese de que a linguagem é um construto público. Vejamos agora o que ele fala a respeito da tese de que as expressões da linguagem denotam coisas do mundo.

$\mathrm{Na}$ tradição analítica, os filósofos sempre tiveram a ambição de explicar a relação entre linguagem e mundo sem a necessidade de postular uma mediação baseada nos estados e processos mentais dos falantes. As noções fregianas de Sinn e Bedeutung tinham exatamente a função de fundamentar uma explicação desse tipo. Com base nelas, é possível desenvolver uma semântica livre dos germes do psicologismo. Pode-se dizer efetivamente que, nos primeiros tempos da filosofia analítica, todos os filósofos que procuravam explicar as propriedades semânticas da linguagem 
estavam interessados numa semântica externalista. E é esse tipo de semântica que é o alvo das mais contundentes críticas de Chomsky. A questão é colocada nos seguintes termos:

\begin{abstract}
Uma boa parte da filosofia contemporânea da linguagem lida com alegadas relações entre expressões e coisas, às vezes explorando intuições sobre as noções técnicas 'denotar', 'referir', 'verdadeiro de' etc. (...) Mas não pode haver nenhuma intuição sobre essas noções (...) Esses são termos técnicos do discurso filosófico com um sentido estipulado que não tem nenhuma parte na linguagem ordinária; é por isso que Frege teve que providenciar um novo significado técnico para “Bedeutung”, por exemplo (CHOMSKY, 2000, p. 130).
\end{abstract}

O que Chomsky denuncia aqui é a artificialidade da noção de denotar, e de outras noções similares. Quando ele diz que não pode haver intuições sobre essas noções, ele está falando do tipo de intuição utilizada na pesquisa empírica, ou seja, do tipo de intuição que advém da observação e da experimentação. Com efeito, as noções técnicas mencionadas acima não são baseadas na observação de fenômenos empíricos. De acordo com Chomsky, alguém pode escolher trabalhar com a hipótese de que expressões denotam coisas do mundo, mas tal hipótese não é justificada em termos empíricos. A noção de denotar tem um significado estipulado. Desse modo, ela pode até muito bem integrar o aparato conceitual de uma teoria normativa, mas nunca poderá ser adequadamente introduzida em teorias que objetivam descrever e explicar o que efetivamente acontece na prática da linguagem. Em particular, ela não pode ser a noção-chave de nenhuma teoria que vise explicar a natureza e o papel das propriedades semânticas das palavras, pelo menos não enquanto as palavras são consideradas em seu uso ordinário.

Chomsky admite que as teorias que nós criamos podem se orientar pelo ideal fregiano de uma linguagem pública com fórmulas bem formadas e uma semântica baseada na noção de denotar, e talvez essa busca por sistemas fregianos seja uma propriedade da nossa faculdade de formar ciência. No entanto, isso não nos diz nada sobre a linguagem natural.

Para explicar como funciona a linguagem natural, segundo Chomsky, é preciso observar, em primeiro lugar, que as palavras possuem feições de dois tipos: feições fonéticas (o som das palavras) e feições semânticas (o significado das palavras) (Cf. CHOMSKY, 2000, p. 125). Tudo o que as palavras fazem (inclusive os nomes próprios) é oferecer as suas feições para que sejam interpretadas pelos falantes. Dessa forma, em primeira instância, é 
com os falantes que as palavras se relacionam, não com o mundo, pelo menos não diretamente. Certamente, as feições semânticas fornecidas pela palavra podem dar condições para que o falante refira coisas no mundo, mas isso já é o resultado do processamento dessas feições pelo falante. Chomsky afirma o seguinte:

Nós temos juízos intuitivos a respeito de expressões e das perspectivas e pontos de vista particulares que elas fornecem para interpretação e pensamento. Além disso, nós podemos seguir estudando como essas expressões e perspectivas entram nas várias ações humanas, tais como referimento. Passando disso, nós entramos no reino do discurso técnico, privado de juízos intuitivos (CHOMSKY, 2000, p. 40).

Dessa forma, fica claro que, do ponto de vista chomskyano, a semântica externalista estava condenada ao fracasso desde o início. Uma correta explicação das propriedades semânticas da linguagem tem que ser uma explicação de como as feições semânticas das expressões são processadas internamente pelos falantes. Em outras palavras, a única explicação satisfatória para os fenômenos semânticos deve ser uma explicação internalista.

Chomsky salienta que o estudo das propriedades semânticas de uma palavra deve se assemelhar ao estudo de suas propriedades fonéticas, quer dizer, o que importa são as interpretações que essas propriedades determinam. Nessa perspectiva, o que se faz com uma palavra sempre depende de como ela é interpretada e sempre há mais de uma forma de se fazer isso. Interpretações diferentes surgem quando aspectos diferentes das feições fornecidas pela palavra são enfocados. Suponhamos, por exemplo, que Pedro e João peguem exemplares de Guerra e Paz numa biblioteca. Uma pergunta que se pode levantar aqui é: eles pegam o mesmo livro ou livros diferentes? Essa pergunta, naturalmente, pode ser respondida de mais de uma forma. Tudo depende da propriedade semântica que é enfocada quando interpretamos a palavra "livro". Podemos enfocar as propriedades materiais ou o componente abstrato. Seja como for, somos nós que escolhemos um foco. A palavra "livro" em si não refere nada. Um livro não tem propriedades de identidade em virtude de sua constituição interna, mas "em virtude do modo como as pessoas pensam, e dos significados dos termos nos quais estes pensamentos são expressos” (CHOMSKY, 2000, p. 16). Desse modo, uma semântica internalista parece mesmo o único modo de explicar como uma palavra pode ser usada para falar de algo no mundo. Ela só pode ser usada assim porque nossa mente é dotada de algoritmos que interpretam as feições 
semânticas da palavra e fazem com que tenhamos certas ações. A investigação naturalista da mente deve esclarecer como são esses algoritmos, esclarecendo também dessa forma como a linguagem nos possibilita executar ações tais como referir e falar sobre o mundo.

A pergunta sobre a referência de uma palavra não faz sentido se não levamos em conta as feições semânticas que nós usamos quando pensamos e falamos a palavra. Segundo Chomsky, "em geral, uma palavra, mesmo a mais simples, não identifica uma entidade do mundo, ou de nosso 'espaço de crenças”" (CHOMSKY, 2000, p. 17). A ideia-chave aqui é que a função básica das palavras é fornecer inputs para sistemas da mente. A função de referir não é uma função que possa ser exercida pela palavra em si, independentemente do processamento interno dos falantes.

Com efeito, Chomsky sustenta que o fato central sobre a linguagem não é que ela é usada para representar o mundo. $O$ fato central sobre a linguagem é que ela nos permite expressar nossas representações internas e interpretar as representações das outras pessoas. Com isso, adquirimos certas perspectivas que usamos para moldar e enxergar o mundo a nossa volta. Essas perspectivas influenciam até o status das coisas nomeáveis. Uma coisa sob um certo ponto de vista pode se tornar uma coisa diferente sob um ponto de vista diferente. Para Chomsky, "termos tais como Londres são usados para falar sobre o mundo atual, mas não há e não é crível que haja coisas-no-mundo com as propriedades dos intrincados modos de referência que o nome encapsula” (CHOMSKY, 2000, p. 37). Com isso, ele quer dizer que não existe uma Londres independentemente das perspectivas que adotamos quando usamos o nome "Londres". Na verdade existem várias Londres, e todas dependem de perspectivas individuais. Londres pode ser tanto uma entidade administrativa como um conjunto de edificações, uma coletividade de seres humanos, um ponto em um mapa etc.

Chomsky dá vários exemplos da complexidade semântica das palavras, querendo com eles mostrar que:

Um item lexical nos fornece um domínio de perspectivas para ver o que nós consideramos as coisas no mundo, ou o que nós concebemos de outros modos; estes itens são como filtros ou lentes, provendo modos de ver as coisas e pensar sobre os produtos de nossas mentes. Os termos em si não referem, pelo menos se o termo referir é usado em seu sentido na linguagem natural; mas as pessoas podem usá-los para ver as coisas, vê-las de pontos de vista particulares (CHOMSKY, 2000, p. 36). 
Nesse sentido, uma das questões mais importantes para a pesquisa internalista sobre a linguagem é a de esclarecer como nossa faculdade de linguagem influencia nossa representação do mundo, ou seja, como nosso modo de interpretar itens lexicais determina nosso modo de ver as coisas. Chomsky explica que todos os itens lexicais, vale dizer, todas as palavras têm propriedades semânticas e só podem ser usadas se essas propriedades forem interpretadas pelos falantes. Esse é o caso até mesmo dos demonstrativos e dos nomes próprios. Ele afirma que:

As observações se estendem para os elementos referenciais mais simples e para aqueles referencialmente dependentes (...) ou para nomes próprios, que têm ricas propriedades semântico-conceituais derivadas em grande parte de nossa natureza, com alguma contribuição da experiência. Algo é nomeado como uma pessoa, um rio, uma cidade, com a complexidade de compreensão que acompanha essas categorias. A linguagem não tem nenhum nome logicamente próprio despido dessas propriedades (...). Nós podemos pensar sobre nomeação como uma espécie de 'feitura de mundos', em algo como o sentido de Nelson Goodman (1978), mas os mundos que nós fazemos são ricos e intrincados e substancialmente compartilhados graças a uma natureza complexa compartilhada (CHOMSKY, 2000, p. 181).

Em suma, quando trata da denotação e da referência de uma palavra, Chomsky se distingue dos externalistas pelo fato de enfatizar dois pontos: 1 . quando $\mathrm{X}$ compreende a palavra W, $\mathrm{X}$ faz uso de suas propriedades; 2 . as propriedades podem incluir feições fonéticas e feições semânticas e, se é assim, as últimas têm um papel em determinar o que $\mathrm{X}$ refere quando usa a palavra W (cf. CHOMSKY, 2000, p. 187).

Naturalmente os externalistas tentam se defender e voltar a carga contra Chomsky, criticando as suas opiniões. Em New Horizons, as críticas que são discutidas mais extensamente são aquelas feitas por Putnam.

Putnam insiste que o uso da linguagem é regulado por fatores externos, nomeadamente feições do mundo e regras de comunidade. São, portanto, esses fatores que o filósofo deve considerar para explicar o funcionamento da linguagem. Desse modo, para Putnam, uma semântica externalista é não só justificada como necessária. Por outro lado, alusões aos estados psicológicos dos falantes não são requeridas para elucidar questões semânticas. O que ele chama de "mentalismo do MIT", movimento no qual 
Chomsky é incluído, estaria assentado em premissas psicologistas equivocadas.

Putnam considera que as teses básicas do mentalismo do MIT foram refutadas quando ele demonstrou que a referência é determinada em parte pela "divisão do trabalho linguístico" e em parte pela "contribuição do ambiente", ambos fatores externos. Tal demonstração é baseada em alguns exemplos, entre eles o conhecido exemplo da Terra Gêmea (cf. PUTNAM, 1973, p. 700-703 e PUTNAM, 1979, p. 223-226). De acordo com esses exemplos, quando alguém dá um nome $\mathrm{n}$ a uma substância $\mathrm{S}$, essa pessoa está nomeando algo que tem certas propriedades essenciais. Dessa forma, $\mathrm{n}$ fica sendo o nome de toda substância que tem as propriedades essenciais de S. É possível, porém, que uma substância $S^{\prime}$ tenha as mesmas propriedades fenomenológicas de $S$, não tendo, porém, suas propriedades essenciais. Dessa forma, n identificará $S$, mas não $S^{\prime}$. O problema é que só um especialista será capaz de distinguir as duas substâncias e, por conseguinte, só ele poderá dizer qual delas pode ser chamada de $\mathrm{n}$. Nesse sentido, o significado de $\mathrm{n}$ depende do trabalho do especialista. Numa comunidade de linguagem, há portanto aqueles que produzem significados com base em seu conhecimento da natureza das substâncias e espécies, e há aqueles que consomem e reproduzem os significados que outros definiram. Em suma, há uma divisão do trabalho linguístico. Com base nisso, pode-se concluir que os aspectos semânticos da linguagem são externamente determinados e não internamente, como defende Chomsky.

Outra crítica de Putnam que Chomsky discute em New Horizons (cf. CHOMSKY, 2000, p. 19-20) é a crítica à ideia de que se pode usar a neurociência para esclarecer questões semânticas. ${ }^{2} \mathrm{O}$ ponto central dessa crítica está na observação de que a neurociência pode descobrir os fenômenos eletroquímicos que ocorrem no cérebro de alguém que usa, por exemplo, a palavra "gato", mas isso não teria nenhuma relevância para esclarecer o significado de "gato". A conclusão de Putnam então é de que, do estudo do cérebro, nada pode ser aprendido sobre a noção de significado.

Chomsky analisa os argumentos de Putnam e mostra que eles não refutam a visão internalista da linguagem. Em relação à utilização da neurociência, ele observa que a análise do cérebro no nível da descrição das suas configurações neurais não é mesmo suficiente para esclarecer questões sobre as propriedades semânticas das palavras. Entretanto, quando essa análise é combinada com uma análise dos aspectos computacionais e

2 Essa crítica aparece em PUTNAM, 1991, p. 41. 
representacionais do cérebro, muitas questões a respeito de nosso uso das propriedades semânticas da linguagem podem ser elucidadas.

Outrossim, e com maior variedade de argumentos, Chomsky rechaça a ideia fundamental do externalismo de Putnam, a ideia de que a cooperação social seja o critério para a determinação da referência de uma palavra. Embora reconheça que a explicação de Putnam é adequada para certas circunstâncias, Chomsky afirma que no argumento da Terra Gêmea, nós não podemos ter nenhuma intuição sobre a questão porque os termos "extensão", "referência" etc. são inovações técnicas que significam o que os seus inventores dizem que elas significam. Ele insiste que a teoria de Putnam "poderia contribuir para especificação de referência somente se houvesse alguma noção coerente de 'referência”' (CHOMSKY, 2000, p. 41). Não obstante, em sua opinião, não é possível dar uma formulação coerente para uma relação R' que supostamente se mantém entre expressões e coisas e está divorciada de condições e circunstâncias particulares de referência.

Chomsky argumenta que o exemplo da Terra Gêmea é deficiente ainda que concordemos em trabalhar com a hipótese de que as palavras denotam. Ele reclama que a constituição química não é o único fator que leva alguém a chamar um líquido de água. O líquido que vem da torneira tipicamente é chamado de "água", o que teve um saco de chá mergulhado nele tipicamente é chamado de chá. Pode ser que ambos os líquidos tenham exatamente a mesma constituição química, e pode ser que alguém chame um de "água" e o outro de "chá", mesmo sabendo disso. Na perspectiva de Chomsky, o uso científico da palavra "água" não é mais legítimo do que o uso do senso comum. Pessoas diferentes podem ter critérios diferentes para chamar algo de "água" e nenhum critério é melhor ou mais correto que o outro. Com efeito, Chomsky afirma que:

Se, por exemplo, Maria acredita que há água em Marte, e lá é descoberto algo que ela vê como água embora tenha uma constituição interna de água pesada ou XYZ, não há nenhuma resposta geral para a questão se a crença dela é correta ou errada (CHOMSKY, 2000, p. 190).

Além disso, ele observa que não é claro a qual linguagem pertence o enunciado "água é $\mathrm{H}_{2} \mathrm{O}$ ". À linguagem ordinária ou à da ciência? $\mathrm{O}$ termo "água" é um termo da linguagem ordinária, mas o termo " $\mathrm{H}_{2} \mathrm{O}$ " é um termo da Química. Para Chomsky, se não há clareza sobre a linguagem à qual o enunciado pertence, não é possível fazer nenhuma afirmação sobre o seu status. 
Um outro ponto em que Chomsky discorda de Putnam é em relação à forma de definir a relação de referir. Putnam afirma que referir é uma relação triádica (a pessoa X refere o objeto Y com o sinal S), onde Y é um objeto do mundo.

Chomsky começa atacando a ideia de que $\mathrm{Y}$ deve ser um objeto do mundo. Ele argumenta que já que as pessoas usam a palavra "Chinês" para se referir à língua de Pequim, então este deveria ser um objeto real do mundo, mas, para ele, esse objeto não existe. Além disso, pela perspectiva chomskyana, a relação de referir é pelo menos tetrádica (X refere $\mathrm{Y}$ com a expressão $\mathrm{E}$ sob circunstâncias $\mathrm{C}$ ) e $\mathrm{Y}$ não precisa ser um objeto real do mundo ou ser tido como tal por X. Segundo ele:

\begin{abstract}
A pessoa $\mathrm{X}$ usa a expressão $\mathrm{E}$ com suas propriedades semânticas intrínsecas para falar do mundo a partir de certas perspectivas intrincadas, focando atenção sobre aspectos particulares dele, sob circunstâncias C, com a 'localidade de conteúdo’ que elas induzem (CHOMSKY, 2000, p. 150).
\end{abstract}

Depois de mostrar a deficiência da argumentação de Putnam, Chomsky ainda considera a tese de que a noção de referir é necessária para explicar as condições da verdade e da falsidade dos enunciados da linguagem. O que os defensores dessa tese alegam é que um enunciado só pode ser considerado verdadeiro se ele descreve ou representa de alguma forma um fato ou um estado de coisas existente. Além disso, supõe-se que um enunciado só pode representar um fato se suas partes denotam partes do fato. Essa era uma das ideias centrais do atomismo lógico de Wittgenstein e Russell, e continua sendo uma ideia influente em toda a filosofia da linguagem de estilo analítico.

Chomsky responde essa alegação ao mostrar que podemos falar que um enunciado é verdadeiro mesmo quando alguns dos seus termos são desprovidos de denotação. Como vimos, por exemplo, de acordo com Chomsky, a afirmação "Chinês é a língua de Pequim" é verdadeira, mas não há nenhuma coisa no mundo que corresponda à palavra "Chinês". Para Chomsky, a verdade de um enunciado depende da interpretação que fazemos das palavras que o compõem, não do pretenso fato de que elas referem coisas no mundo. Depende, assim, em primeiro lugar, de fatores internos, não de fatores externos.

Essas são as principais críticas que Chomsky faz à tese de que as palavras denotam coisas do mundo. Os argumentos que ele usa em sua crítica têm uma mensagem comum que pode ser expressa nos seguintes termos: as 
palavras não apontam para as coisas do mundo, elas apenas abrem janelas; as pessoas que olham por essas janelas é que apontam, se assim desejarem. Essa mensagem é enfatizada toda vez que Chomsky lembra que as palavras têm propriedades semânticas que devem ser interpretadas pelos falantes para que eles possam utilizá-las. É, portanto, como fornecedoras de informação que Chomsky, em primeiro lugar, caracteriza as palavras, e não como instrumentos de apontar para o mundo. Esse modo de conceber a função precípua das palavras não exclui os nomes próprios.

\section{Referências Bibliográficas}

BURGE, T. "Individualism and the mental". In: FINCH, P. et al. (ed.), Midwest Studies in Philosophy, vol. IV: Studies in Metaphysics. Minneapolis: University of Minnesota Press, p. 73-121, 1979.

CHOMSKY, N. Language and mind. 1ำ ed. New York: Harcourt, Brace \& World, Inc. 1968.

“A Review of B. F. Skinner's Verbal Behavior”. In: FODOR, J. \& KATZ, J. (eds). The Structure of Language: readings in the philosophy of language. New Jersey: Prentice Hall, Inc., p. 547-578, 1964a.

"A Transformational Approach to Syntax". In: FODOR, J. \& KATZ, J. (eds). The Structure of Language: readings in the philosophy of language. New Jersey: Prentice Hall, Inc., p. 211-245, 1964 b.

. Studies on Semantics in Generative Grammar. $3^{\circ}$ ed. The Hague: Mouton \& Co. N. V. Publishers, 1976.

New horizons in the study of language and mind. Cambridge:

Cambridge University Press, 2000.

GARDNER, H. A Nova Ciência da Mente. 3oe ed. São Paulo: Edusp, 2003.

MITKOV, R. (ed.). The Oxford Handbook of Computational Linguistics. Oxford: Oxford University Press, 2003.

PUTNAM, H. "Meaning and Reference". In: The Journal of Philosophy, vol. 70, n⿳⺈ 19, 1973, p. 699-711.

"The Meaning of 'Meaning". In: Mind, Language and Reality (Philosophical Papers, Vol. 2), 2o ed., Cambridge: Cambridge University Press, 1979.

1991.

Representation and Reality. Cambridge, MA: A Bradford Book,

QUINE, W. V. O. Palavra e Objeto. Tradução de Sofia Inês Albornoz Stein e Desidério Murcho. Petrópolis: Vozes, 2010.

SMITH, N. "Prefácio". In: CHOMSKY, N. New horizons in the study of language and mind. Cambridge: Cambridge University Press, 2000. 
WITTGENSTEIN, L. Investigações Filosóficas. Tradução de Marcos G. Montagnoli. 2oe ed. Petrópolis: Vozes: 1996 (Coleção Pensamento Humano).

EMAlL: cicero@lia.ufc.br

RECEBIDO: Junho/2011 APROVADO: Novembro/2012 